\title{
Review: Dual Band Microstrip Antennas for Wireless Applications
}

\author{
Rakesh Kumar Bajpai ${ }^{1}$, Rajeev Paulus ${ }^{1}$, Ashish Singh ${ }^{2}$, Mohammad Aneesh $^{3}$ \\ ${ }^{1}$ Department of Electronics and Communication, Sam Higginbottom Institute of Agriculture, Technology \& Sciences, \\ Allahabad, 211007 India \\ ${ }^{2}$ Department of Electronics and Communication, NMAM Institute of Technology, Nitte, Karnataka, 574110, India. \\ ${ }^{3}$ Department of Electronics and Communication, Babasaheb Bhimrao Ambedkar University, Lucknow 226025 India
}

\begin{tabular}{|c|c|}
\hline Article Info & ABSTRACT \\
\hline Article history: & In this manuscript, a review of dual band microstrip antennas for wireless \\
\hline Received Jan 14, 2018 & $\begin{array}{l}\text { communication is presented. This review manuscript discusses regarding the } \\
\text { geometric structures, different methods of analysis for antenna }\end{array}$ \\
\hline Revised Apr 23, 2018 & characteristics, and different types of wireless applications. \\
\hline Accepted May 18, 2018 & \\
\hline
\end{tabular}

Keyword:

Dual Band

Microstrip Patch Antenna

Wireless Communication

\section{Corresponding Author:}

Ashish Singh,

Department Electronics and Communication Engineering,

NMAM Institute of Technology,

Nitte, Karnataka, 574110, India.

Email: ashsin09@rediffmail.com

\section{INTRODUCTION}

In modern wireless communication system role of microstrip patch antennas are tremendously increasing due to its demand wide range applications in radar, aircraft, missiles, satellite communications, bio-medical telemetry, remote sensing and different other wireless applications. Due to its wide range of applications in wireless application researchers and scientists has worked on this field. The concept of microstrip patch antenna has been reported by many researchers and the earliest introduced sources were given by Greig and Englemann [1] and Deschamp [2]. At that time spontaneous radiation from the narrow microstrip line was appreciated by various scientists and researchers and thereafter, lot of efforts were made to reduce the dimensions of the substrate and conducting strip to further enhance the radiation effects and bandwidth.

The microstrip patch antennas are similar to parallel plate capacitors. As capacitor contains two metallic parallel plates between these plates dielectric substrate is placed whereas in microstrip antennas bottom side of the dielectric substrate has metallic plate of infinitely extend to form the ground and at top is radiating patch. The size of the patch depends on the wavelength of radiating signal. The radiating patch and ground is composed of conducting metals such as copper or gold and these can be of different geometry depending on the radiating frequency. Figure 1 shows the general geometry of patch antenna. The different possible shapes of the radiating patches are such as rectangular, circular, triangular, semi-circular, sectoral square ring and angular ring are shown in Figure 2. Generally, the microstrip patch antennas are made of metallic patch of larger width and low dielectric substrate $\varepsilon_{\mathrm{r}}$ with thicker the height of substrate h. Further, to enhance fringe fields for the account of radiation of patch antenna the dielectric constant $\varepsilon_{\mathrm{r}}$ of the substrate 
should be below $<2.5$. The microstrip patch antenna is excited by $50 \Omega$ coaxial connector or microstrip line. The antennas resonating frequencies is effected by the dimension of the radiating patch are substrate height $h$, length of the patch $\mathrm{L}$, and relative dielectric constant $\varepsilon_{\mathrm{r}}$.

The microstrip patch antenna has lots of merits than other conventional antenna for communication system. Most of these antennas are low profile planar configuration which has very thin radiating patch placed in $\mathrm{x}$ and y coordinates direction of any shape on the dielectric substrates, smaller in volume as well as lighter in weight. Due to these features it is easily conformal to the host surface. Further, uses of printed circuit technology make it easier for mass production and this also reduces the fabrication cost. These antennas are easily integrated with microwave integrated circuit on the same dielectric substrates, capable of both linear and circular polarization and also utilized for dual and triple frequency operation. Due to these advantages microstrip patch antenna are used in the telemetry and communications antennas on missiles, radar altimeter, satellite communication, satellite imaging system, synthetic aperture radar (SAR) and microwave sensors applications etc [3-4].

The Microstrip antennas are the emerging technologies in the field of electronics. As these antenna can be fabricated on the printed circuit boards. However, these antennas are still in the development phase, so lots of new designs and analysis still had to be done. Again, this antenna can be achieved using various techniques such as loading of slot and notch, loading of active devices, stub loading, by using different feeding techniques, coplanar and stacked structures and meta-materials etc.. For designing, simulating and analyzing the microstrip antenna, there are several simulating software's are available such as IE3D, HFSS, and CST etc.

The microstrip patch antenna can fulfil the demand of various wireless applications. In this regard, review of the research papers for previous ten years manuscripts are done. A review paper is divided into designs of patch antenna, analysis techniques, applications and results at last section conclusion with future scope.

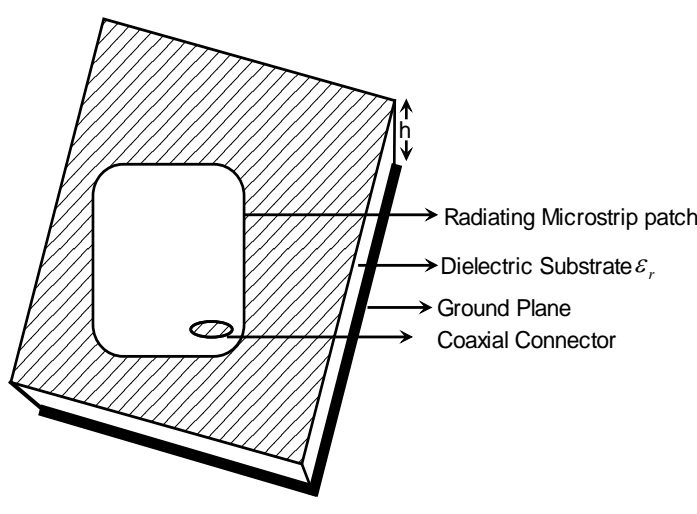

Figure 1. Geometry of microstrip patch antenna
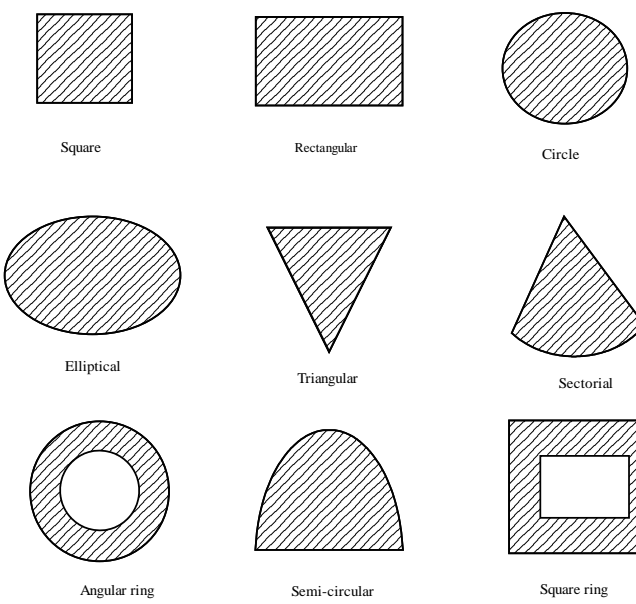

Circle
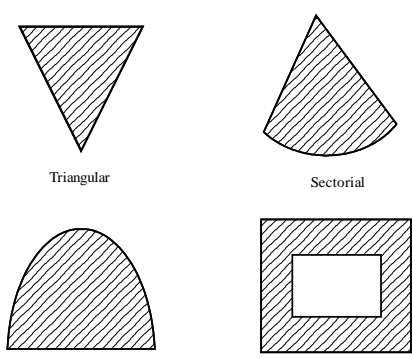

Semi-circular

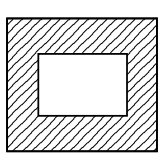

Square ring

Figure 2. Different shapes of microstrip patch antenna. provided

\section{DESIGNS OF PATCH ANTENNAS}

Design and development of patch antenna for wireless communication has been discussed in this section. As it has been know that patch antenna can be placed on PCB for various communication devices. So, keeping this in mind researchers worked on various patch antenna designs for wireless applications.

In 1998, rectangular patch antenna for dual frequency operation was reported by Fayyaz et al. [5] in which designed antenna was fed by a microstrip line on the onside of the radiating patch while on other side of edge is shorted.

In 2001, A dual-frequency circular MSA design using single-layer, single-feed and loaded with open ring slot was reported by Jan [6]

In 2003, Chen et al. [7] reported the planar inverted-F antenna (PIFA) for the dual band applications and founded that maximum antenna gain of $2.5 \mathrm{dBi}$ for both $900 / 1800 \mathrm{MHz}$ band operations.

A compact antenna was proposed by Lin \& Huang [8], they observed the $S_{11}$ mode are generated through square patch while $S_{12}$ mode is activated by angular patch. After that, J.W. Wu et al. [9] investigated 
rectangular slot loaded antenna for dual-broadband operation in wireless local area network WLANs and obtained impedance bandwidth for two resonating frequency $2.4 \mathrm{GHz}$ and $5 \mathrm{GHz}$ as $11 \%$ and $24.6 \%$ respectively. Afterward, Zheng and Fang [10] demonstrated dual characteristic on loading two L-designed lower rectangular antenna for wireless communication devices. Further, Chang et al. [11] proposed planar quasi - Yagi antenna of wireless application and observed that antenna had dual band operation.

In 2006, Wong et al. [12] designed antenna which has the radiating structure of T- shaped and it has the radiating patch greater than ground plane which generates two resonating modes. In same year, Sze [13] proposed a circular aperture antenna with CPW fed that has slit back patch and they observed that broadside far-field pattern at both frequency bands. In same year, Guterman et al. [14] reported dual band E- shaped radiating surface back to back antenna that can be embedded in the laptops and observed two frequencies can be tuned at 1.2 to $3.5 \mathrm{GHz}$, frequency.

In 2007, Khaleghhi [15] described dual band antenna having meander line with backed ground plane for WLAN and measured $11 \%$ and $6 \%$ impedance bandwidth for lower and upper resonance frequency. Latter, Wong et al. [16] designed antenna in such a way that narrow strip generate higher frequency bands whereas other generate lower frequency band and antenna work for personnel assistant (PDA).

In year 2008, Chang [17] presented compact vertical patch antenna for WLAN operation. Latter, Callaghan and Batchelor [18] proposed disk shaped antenna with shorting wall at the edges of the patch and fundamental modes is generated at $37 \mathrm{~mm}$ of air as substrate.

In year 2009, Liu and Chen [19] demonstrated twin stepped patch radiators for WLAN applications. After then, Wang et al. [20] designed electromagnetically coupled antenna for dual band operation which is applicable for satellite communications. Latter, He [21] presented a high gain antenna was designed of a fork for WLAN application.

In year 2010, Hsu [22] presented E-shaped patch antenna having two resonating frequency at 2.4 and 3.5 GHz for wireless communication. Latter, Shanmuganantham and Ragharan [23] proposed a novel square patch antenna for bandwidth improvement and size reduction of the antenna.

In year 2011, Peng and Ruan [24] presented an antenna for Bluetooth and DCS applications which has been obtained from dual inverted L-shaped stub and antenna is excited though a microstrip line fed. Thereafter, Sim and Cai [25-26] designed microstrip-fed polygon slot structure for wireless local area network applications and loaded narrow slots on rectangular patch which has L-geometric slits for wireless applications. Esfahlani [27] demonstrated the frequency ratio of 4.75 can be obtained from printed patch antenna while applying coaxial fed and shorting pin on the radiating patch. Ma and Row [28] designed the dual band patch antenna which has two dielectric substrate overlapped each other and excited via a sma connector.

In 2012, Li [29] proposed dual band antenna that has L-shaped and arc-shaped stub as radiating structure whereas Luo [30] reported dual band antenna for wireless applications which has L-shaped slots. Leal et al. [31] provided the effective way of reducing size of the patch antenna using U- shaped resonator.

In year 2013, Lee [32] proposed the techniques for size reduction and wide frequency on microstrip antennas design. Further, Ansari et al. [33] proposed the analysis of disk shaped antenna with L-strip feeding using method of movement and circuit theory concepts. After that, Moosazadeh and Esmati [34] presented the small planar microstrip-fed square radiator using slotted conductor backed plane.

In year 2014, trapezoidal shaped antenna was proposed by Boney [35] which has half ground and antenna is excited by the meander line fed. Further, Addaci [36] proposed an antenna for dual band operation which has PIFAs that are placed closed to each other.

In year 2015, Liu [37] presented the design of stacked E- and U-shaped patches to produce dual band at 2.6 and $3.5 \mathrm{GHz}$ with peak gain of 7.1 and $7.4 \mathrm{dBi}$. Further, Wang [38] illustrated the patch antenna design that is utilized for wireless communications, the geometry is notches loaded that help in providing dual band at 1.45 and $2.35 \mathrm{GHz}$.

In year 2016, Guha and Kumar [39] have demonstrated the comparison between dielectric resonator and patch antenna using different feeding techniques. They designed the patch antenna on circular geometry and resonator on solid cylinder. Later on, Sabapathy [40] design patch antenna of Yagi Uda shaped with defected ground and analysis the antenna performance by varying the parasitic elements. Further, W.-Q. Cao [41] have designed the antenna of mushroom shaped on circular patch that is utilized for dual band operation and achieved the operating frequency at $4.42 \mathrm{GHz}$ and $5.74 \mathrm{GHz}$. Thereafter, Salih and Sharawi [42] designed compact U-shaped patch antenna on Roger RO4350 dielectric substrate with defected ground plane and found that antenna resonates at $2.4 \mathrm{GHz}$ and $5.2 \mathrm{GHz}$. Further, Shi [43] presented dual band patch antenna that resonates at two resonating frequencies i.e., 2.5 and $3.5 \mathrm{GHz}$ and these bands was achieved because of stacked patches with angular slot.

In year 2017, Zhang [44] proposed a patch antenna of two U-shaped in such a manner that second U-shape is inside the bigger U-shape. Therefore, the combine geometry produced dual band operation. 


\section{ANTENNAS DESIGN ANALYSIS}

To design the antennas are nowadays very easy since one have various simulation tools such as CST MWS, HFSS, and IE3D. These simulation tools work of different analysis approach such as finite element method (FEM), method of moments (MoM), multilevel fast multi-pole method (MLFMM) and shooting boundary ray (SBR), finite element integral equation, method of moments (MoM) based electromagnetic (EM) software and FIDELITY finite-difference time-domain (FDTD) respectively. After that in general the paper compares there results with simulation and experimental results. Further, various scientist and researchers has proposed other analysis techniques like artificial neural techniques (RBFNN, MLP etc.) and circuit theory concept. From the traditional analysis approaches such as transmission line model, cavity model, and multiport network model are reference for the above reported approaches or same way or the other they are correlated to each other. In this view, some different patch antenna analysis techniques presented by various scientist/ researches are discussed in the section.

In 2002, A dual band patch antenna using parallel genetic -algorithm for wireless communication was reported by Villegas et al. [45].

In Shivnarayan and Vishvakarma [46] designed a notch on the rectangular patch and also given its theoretical analysis and they observed the frequency ratio variation due to the notch loading.

Latter, Chou [47] presented the analysis of patch antenna design for WLAN and DSRC applications using genetic algorithm.

Ansari [48] designed six vertical and three horizontal slots in such a way that three U-shaped in side each other and these slots play vital role in deciding the antenna characteristics.

Mishra [49] designed the L- shaped slot on the disk patch radiator and analysis the results using circuit theory concept.

Singh [50] presented the analysis of symmetrical notches and shorting loaded patch antenna and present equivalent circuit diagram by which VSWR and return loss is calculated.

Singh [51] analyzed the half disk patch antenna loaded with shorting pin and excited via a L-strip feeding using circuit theory concept. Singh et al. [52] proposed the analysis of F-shaped narrow strip antenna similar to monopole antenna as radiation pattern.

In year 2016, K. Noguchi [53] proposed patch antenna of E-shaped using modal theory and designed the equivalent circuit diagram further they have given the parametric analysis E-shaped antenna theoretically. Thereafter, Liu [54] reported the dual band patch antenna of ring shaped and analysed the designed antenna using cavity model.

\section{ANTENNA APPLICATIONS}

In this section, patch antenna has been discussed according to there application in various fields of wireless communication such as bio-telemeter, data telemeter wireless sensor networks and other wireless applications.

In 1995, Salvador [55] reported patch antenna that can be utilized in S and X bands applications which has array of four patches arranged in such a manner that there is spacing between two patches.

In1998, Lazzi [56] investigated experimental and numerical results for high gains, low SAR signal band and dual band microstrip patch antennas covering the frequency band (825 -895 MHz and1830-1930 $\mathrm{MHz}$ ) .

In 2000, Lelaratne and Langley [57] investigated a single layer, multi band microstrip patch antenna operating over the frequency $1.6-2.5 \mathrm{GHz}$.

In 2001, Tong et al. [58] reported a dual band antenna for GSM and DCS applications, its radiating structure is overlapped over two different dielectric substrates. Thereafter, Shum and Luk et al. [59] reported dual band L-probe patch antenna operating in GSM/PCS systems.

In 2003, Yeh [60] reported compact dual bond planes inverted F-shaped antenna GSM/DCS application. , Latter, Chen [61] reported the PIFA antenna for the dual band operation in mobile communication and investigated that maximum antenna gain of $2.5 \mathrm{dBi}$ for both 900/1800 band operations.

In 2004, Jung and De Flaviis [62] observed dual frequency operation for WLAN application by using rectangular patch with 4-bridges. Further, Ho-Yung Kim [63] reported patch antenna with shorting wall for wireless applications. Afterwards, S.H. Choi [64] demonstrated dual frequency patch having a backed microstrip line for industrial, scientific and medical radio and measured radiation patterns at 2.4 and 5.8GHz. After that, dual frequency MSA for high precision for GPS application was reported by Broccia [65].

In 2005, Hwang et al. [66] developed dual band printed antenna for CDMA (824-849MHz) and PCS $(1750-1870 \mathrm{MHz})$ band and measured maximum radiation gains of 0.94 and $1.89 \mathrm{dBi}$ for lower $\mathrm{Q}$ appear resonance frequency respectively. 
In 2006, Lim and Leung [67] discussed dual wide band rectangular dielectric resonator antenna (BRA) and measured return loss, antenna gain and pattern radiation. Joseph et al. [68] proposed a compact dual band antenna for GSM and Bluetooth applications with linear polarization

In 2007, Sim and Tu [69] proposed slotted planner inverted-F antenna (PIFA) for WLAN application. Latter, Huang [70] studied dual frequency narrow strip antenna energised through electromagnetically coupled fed for WLAN and measured 3.4\% and 13\% bandwidth for upper and lower resonance frequency. Thereafter, Tao [71] presented dual band slot antenna for WLAN application and investigation experimentally its impedance bandwidth, radiation pattern and gain. Afterward, Encheng [75] reported printed microstrip antenna for dual frequency which has dielectric substrate of organic material for WLAN communication. In same year, Ren [72] demonstrated a compact T- shaped patch antenna for wireless communications. Thereafter, W. C. Liu [73] presented G-shape patch with CPW feed for dual band operation.

In year 2008, Rmili and Floch [74] demonstrated the design V-shaped patch for DCS/ Bluetooth applications. Latter, Ren [75] proposed the patch antenna that covers the required bandwidth of $(2.4-2.485 \mathrm{GHz})$ and $(5.15-5.825 \mathrm{GHz})$ with satisfactory radiation characteristics.

In year 2009, Lee [76] presented U-shaped patch antenna for wireless communications. Subsequently, Zhang [77] reported double T-shaped slot antenna for radio frequency identifications applications. Thereafter, Zeng and Chu [78] presented a slotted coupled antenna for dualband passive radio frequency identification (RFID). Latter, Choi [79] reported a novel K-shaped patch antenna for WLAN applications and measured gain ranging from 3.66 to $4.58 \mathrm{dBi}$. After then, Wang [80] described about the use of organic material as dielectric substrate for printed patch antenna in various wireless applications.

In year 2010, Shanmuganantham and Ragharan [23] proposed a novel square patch antenna for bandwidth improvement and size reduction of the antenna. Further, Park [81] reported a open stub microstrip antenna for dual frequency operation that can be used for different wireless applications.

In year 2011, Sim and Cai [25] designed microstrip-fed polygon slot antenna for WLAN applications in the 2.4/5.2/5.8 GHz bands. Panda and Kshetrimayum [82] presented narrow patch placed over dielectric substrate with microstrip line feeding used for wireless communications. A compact notched CPWfed wide-slot antenna for wireless local area network (WLAN) and worldwide interoperability for microwave access (WiMax) applications was proposed by Lin [83].

In year 2012, Lu and Liu [84] designed reactive loaded array antenna microstrip line fed having $50 \Omega$ with gain of $14.1 \mathrm{dBi}$ for $4 \mathrm{G}$ and WiMax applications. After that, Batra and Sharma [85] the demonstrated the method to combine the aperture and DRA patch antenna can utilized in wireless applications. Further, Salar Rahimi [86] designed electromagnetic coupled band gap antenna using circular patch that are place on dielectric evenly like an array. Later on, Tan and Ismail [87] designed compact dualband tag antenna for radio frequency identification (RFID) systems whereas Xiong and Gao [89] proposed the design of compact dual frequency microstrip antenna in such a way that it can be utilized for multi-band operation in wireless operations.

In year 2013, Ojaroudi and Ojaroudi [90] designed reactive loaded patch antenna that is energised by coplanar wave guide used for wireless communication such as PCS/ Bluetooth applications. Further, Chen [91] investigated an antenna design for GPS and UTMS which is loaded with shorting pin on the radiating patch. In same year, A novel compact reconfigurable patch antenna for tuning two frequency bands of $3 \mathrm{G}$ and $4 \mathrm{G}$ mobile communication was proposed by Bekali and Essaaidi [34]. Ying song Li [92] studied the use of shorting wall and capacitance for enhancing the characteristics of microstrip antenna for wireless local area network (WLAN) applications.

In year 2014, Chakraborty [93] designed rectangular microstrip patch antenna that has two narrow rectangular apertures on the radiating surface as well as it aperture on the ground plane which can be utilized for WLAN Application. Later, Lin-Chuan Tsai [94] investigated a bow-tie-shaped CPW-fed slot antenna consists of a coaxial connector and two conducting strips for wireless communication applications.

In year 2015, Sharma [95] designed $\pi$ slot on the patch antenna for dual band operation using aperture feeding and its size reduce on loading the slots, so can be used for wireless applications. Latter on, Bakariya [96] proposed the design of non contacting feeding to patch i.e., electromagnetic coupling between the V-shaped radiating patch and fed microstrip, it can be utilized for wireless applications such as bluetooth, WiMax, and WLAN.

In year 2016, Mathew [97] demonstrated the designed patch antenna that has V-shaped slot that is etched on circular geometry and they found that antenna resonate at two different frequencies i.e., 2, 3.5 and 5.6 GHz having gain of 4.4, 3.5 and $2.8 \mathrm{dBi}$ respectively. Thereafter, Zhu [98] presented the U-shaped patch antenna for dual band operation and they observed that antenna resonates at two frequencies i.e., 2.45 and 5.8 $\mathrm{GHz}$ having gain of 1.37 and $4.37 \mathrm{dBi}$ respectively. 
In 2017, Zhang [44] designed antenna for 4G communication that has gain of $7.3 \mathrm{dBi}$ and has two operating band at 1.9 and $2.6 \mathrm{GHz}$.

\section{CONCLUSION}

It is concluded that the microstrip patch antenna holds promising future. The dual band, wide band, and broad band antennas can fulfils the demand of various wireless applications. It has been observed from the last ten years papers that researches on microstrip patch antenna was increased and since large number of paper were reported. In these reported papers different shapes of antennas has been proposed by various research and scientists. In which E-shaped, C-shaped, U-shaped, F-shaped and H-shaped are disused more frequently by the scientists. Further for the antenna characteristics analysis were done by various scientists/researchers. They applied different techniques such as artificial neural network (RBFN, MPLN etc.) circuit theory concept, and simulation part is lacking to explain the desire characteristics patch for uneven shaped geometries. Thereafter, more different ANN tool, after that most of the paper compared there experimental results with simulated (HFFS, CST, AWR, and IE3D) results, few of them compare their results with circuit theory concept and ANN results. In this view, lots of papers has been proposed every year but still there is more possibility of more patch antenna to be designed for different shapes and geometries. Furthermore, still analysis techniques and circuit theory concept has to be proposed for patch antennas. The application of the patch antenna is also considerable part i.e. it should be lying in microwave bands.

\section{REFERENCES}

[1] D. D. Greig and H. F. Engleman, "Microstrip -a new transmission technique for the kilomegacycle range," Proceeding IRE, 40, pp. 1644-1650, 1952.

[2] G. A. Deschamps, "Microstrip microwave antennas," $3^{\text {rd }}$ USAF Symposium on Antennas, 1953.

[3] B.K. Pandey, A. K. Pandey, S B Chakrabarty, S Kulshrestha, A L Solanki, and S. B. Sharma, "Dual frequency single aperture microstrip antenna element for SAR applications,” IETE Technical Review, Vol. 23, No.6, pp.357366, 2006.

[4] T. Haagenson, S. Noghanian, P d. Leon, and Yi-hsiang Chang, "Textile antennas for spacesuit applications: Design, simulation, manufacturing, and testing of textile patch antennas for spacesuit applications," IEEE Antennas and Propagation Magazine, Vol. 57, pp.64-73, 2015.

[5] N. Fayyaz, E. Shin and S. S. Naeini, "A novel dualband patch antenna for GSM band,” Antenna and Propagation for wireless Communications, IEEE-APS conf., pp. 156-159, Nov. 1998.

[6] J.-Y. Jan, "Low profile dual frequency circular microstrip antenna for dual ISM bands," Electronics Letter, Vol.37, pp.999-1000, Aug.2001.

[7] H. T. Chen, K. L Wong and T. W. Chiou, "PIFA with a meandered and folded patch for the dualband mobile phone application,” IEEE Trans. Antenna Propagat., Vol. 51, pp. 2468-2471, Sept. 2003.

[8] S. Y. Lin and K. C. Huang, “A compact microstrip antenna for GPS and DCS application,” IEEE Trans. Antennas and Propagat., Vol.53, pp.1227- 1229, Mar. 2005.

[9] J. W. Wu, Y. D. Wang and J. H. Lu, "Novel dual broadband rectangular slot antenna for 2.4/5- GHz wireless communication,” Microw. Opt. Technol. Lett., Vol.46, pp.197-201, Aug. 2005.

[10] Y. S. Zheng and S. J. Fang, "Dualband rectangular patch antenna with a pair of L-shape slots for WLAN for Application,” Microwave, Antenna, propagation and EMC Technologies for Wireless Communications, IEEE Int. Symp., Vol.1, pp. 185-187, Aug. 2005.

[11] D. C. Chang, C. B. Chang and J. C. Liu, "Modified planar quasi-Yagi antenna for WLAN dualband operations," Microw. Opt. Technol. Lett., Vol.46, pp. 443-446, Sept. 2005.

[12] Kin-Lu Wong, Yuan-Chih Lin and Ting-Chih Tseng, "Thin internal GSM/DCS patch antenna for a portable mobile terminal,” Antenna and Propagation, IEEE Trans., Vol. 54, pp. 238-242, Jan. 2006.

[13] J. Y. Sze, C. I. G. Hsu and J. J. Jiao, "CPW fed circular slot antenna with slit back-patch for 2.4/5 GHz dualband operation,” Electronics Letters, Vol.42, pp.563-564, May 2006.

[14] J. Guterman, Y. R. Samii, A. A. Moreira and C. Peixeiro, "Quasi omnidirectional dualband back-to-back Eshaped patch antenna for laptop applications,” Electronics Letters, Vol.42, pp.845-847, July 2006.

[15] A. Kharleghi, "Dualband meander line antenna for wireless LAN communication," IEEE Trans. Antenna and Propagat., Vol.55, pp.1004-1009, Mar. 2007.

[16] Kin-lu Wong, Yuan-Chih and Brain Chen, "Internal patch antenna with a thin air layer substrate for GSM/DCS operation in a PDA phone,” Antenna and Propagation, IEEE Trans., Vol.55, pp.1165-1172, April 2007.

[17] F. S. Chang, K. C. Chao, C. H. Lu and S. W. Su, "Compact vertical patch antenna for dualband WLAN operation,” Electronics Letters, Vol.44, pp.612-613, May 2008.

[18] P. Callaghan and J.C. Batchlor, "Dualband pin patch antenna for Wi-Fi applications," Antennas and Wireless Propagation Letters, IEEE, Trans., Vol.7, pp.757-760, Aug. 2008.

[19] W. C. Liu and J. K. Chen, “Dualband twin stepped-patch monopole antenna for WLAN application,” Electronics Lett., Vol.45, pp.929-931, Aug.2009. 
[20] Zhongbao Wang, Shaojun Fang, Shiquiang Fu, and Shanwei Lu, "Dualband probe-fed stacked patch antenna for GNSS applications,” Antennas and Wireless Propag. Lett., IEEE, Vol.8, pp. 100-103, 2009.

[21] X. He, S. Hong, H. Xiong, Q. Zhang and E. M. M. Tentzeris, "Design of novel high gain dualband antenna for WLAN applications,” Antennas and Wireless Propagation Letters, IEEE, Vol.8, pp. 798-801, 2009.

[22] Heng-Tang Hsu, Fang-Yao Kuo, and Ping-Hung Lu, "Design of WiFi/WiMAX dualband E-shaped patch antennas through cavity model approach,” Microw. Opt. Technol. Lett., Vol.52, pp.471-474, Feb. 2010.

[23] T. Shanmuganantham and S. Ragahavan, "A novel dualband square patch antenna for wireless applications," Microw. Opt. Technol. Lett., Vol.52, pp.1513-1516, July 2010.

[24] L. Peng and C.-L. Ruan, "A microstrip fed patch antenna with two parasitic invert Lstubs for dual-band WLAN applications,” Wireless Personal Communications, Vol. 57, Issue 4, pp 727-734, April 2011.

[25] C.-Y.-D. Sim and F.-R. Cai, "Rectangular slot antenna design with two L-shaped slits for WLAN/WiMAX applications,” Microw. Opt. Technol. Lett., Vol. 53 pp. 987-991, May 2011.

[26] C.-Y-D. Sim and F.-R. Cai, "Microstrip-fed polygon slot antenna design for WLAN applications," Microw. Opt. Technol. Lett., Vol. 53, pp.1394-1398, June 2011.

[27] S.H.S. Esfahlani, A. Tavakoli and P. Dehkhoda, "A compact single-layer dual-band microstrip antenna for satellite applications,” Antennas and Wireless Propagation Letters, IEEE, Vol. 10, pp. 931 - 934, 2011.

[28] Shun-Lai Ma and Jeen-Sheen Row, "Design of Single-Feed Dual-Frequency Patch Antenna for GPS and WLAN Applications," Antennas and Propagation, IEEE Transactions, Vol. 59, pp.3433 - 3436, September 2011.

[29] R.-H. Li, X.-W. Shi, N. Zhang, Y.-F. Wang and Y.-J. Wang, "A novel compact dual-band antenna for WLAN applications,” Microw. Opt. Technol. Lett., Vol.54, pp. 1476-1479, June 2012.

[30] Y. Luo, Y.-Z. Yin, Y.-Y. Guo and Y. Zhao, "A dual-wideband antenna with an open L-slot for WLAN/WiMAX applications,” Microw. Opt. Technol. Lett., Vol. 54, pp. 1499-1502, June 2012.

[31] R. Flores-Leal, H. Jardon-Aguilar, A. Tirado-Mendez andR. Acevo-Herrera, "Reduced microstrip slot multiband antenna with A U-shaped resonator for WLAN applications,” Microw. Opt. Technol. Lett., Vol.54, pp. 26842689, December 2012.

[32] J. Lee, Y. Liu and H. Kim, "Miniaturized dual-band antenna for wireless local area network," Microw. Opt. Technol. Lett., Vol. 55, pp. 850-852, April 2013.

[33] J. A. Ansari, A. Mishra, N. P. Yadav, P. Singh and B. R. Vishvakarma, "Analysis of L-shaped slot loaded circular disk patch antenna for satellite and radio telecommunication," Wireless Personal Communications, Volume 70, pp. 927-943, May 2013.

[34] Y. K. Bekali and M. Essaaidi, "Compact reconfigurable dual frequency microstrip patch antenna for 3G and 4G mobile communication technologies,” Microw. Opt. Technol. Lett., Vol.55, pp.1622-1626, July 2013.

[35] M. Boney, S. K. A. Rahim, R. Dewan and B. M. Sa'ad, "Dual band trapezoidal antenna with partial ground and meander line feed for GPS and WIMAX applications,” Microw. Opt. Technol. Lett., Vol. 56, pp. 497-502, February 2014.

[36] R. Addaci, K. Haneda, A. Diallo, P. Le Thuc, C. Luxey, R. Staraj, P. Vainikainen, "Dual-band WLAN multiantenna system and diversity/MIMO performance evaluation,” Antennas and Propagation, IEEE Trans., Vol. 62, pp. 1409 - 1415, March 2014.

[37] S. Liu, W. Wu and Da-G. Fang, "Single-feed dual layer dual band E shaped and U-slot patch antenna for wireless communication application,” IEEE Antenna and Wireless Propagation Letters, Vol. 15, pp.468-471, July 2015.

[38] C.-J. Wang, M-H. Shih, and L.-T. Chen, “A wideband open slot antenna with dual band circular polarization,” IEEE Antennas and Wireless Propagation Letters, Vol. 14, pp. 1306-1309, 2015.

[39] D. Guha and C. Kumar, "Microstrip patch versus dielectric resonator antenna bearing all common used feeds: An experimental study to choose right elements,” IEEE Antennas and Propagation Magazine, Vol. 58, pp. 45-55, Feb 2016.

[40] T. Sabapathy, M. Jusoh, R. Badlishah Ahmad, M.R. Kamarudin, and P. J. Soh, "A ground plane truncated, broadly steerable Yagi-Uda patch array antenna,” IEEE Antennas and Wireless Propagation Letters, Vol. 15, pp. 1069-1072, 2016.

[41] W.-Q. Cao, "Compact dual band dual mode circular patch antenna with broadband unidirectional linearly polarized and omnidirectional circularly polarized characteristics,” IET Microwave, Antennaa and Propagation, Vol.10, pp.223-229, 2016.

[42] A. A. Salih and M. S. Sharawi, "A dual band highly miniaturized patch antenna," IEEE Antennas and Wireless Propagation Letters, Vol. 15, pp.1783-1786, 2016.

[43] W. Shi, Z. Qian, and W. Ni, "Dual band stacked annular slot/patch antenna for omnidirectional radiation,” IEEE Antennas and Wireless Propagation Letters, Vol. 15, pp. 390-393, 2016.

[44] X. Y. Zhang, Y. Zhang, Y. Mei, and W. Duan, "Low-profile dual band filtering patch antenna and its application to LTE MIMO system,” IEEE Trans. Antennas and Propagation, Vol. 65, pp.103-113, 2017.

[45] F. J. Villegas, T. Cwik, Y. R. Samii and M. Manteghi, "Parallel genetic algorithm optimization of a dualband patch antenna for wireless communications," IEEE Trans. Antenna Propagat., Vol. 1, pp. 334-337, 2002.

[46] Shivnarayan and B. R. Vishvakarma, "Analysis of dualband patch antenna for mobile communications," Microw. Opt. Technol. Lett., Vol. 47, pp. 558-564, Dec. 2005.

[47] H. T. Chou, Y. C. Huo and W. J. Liao, "A dualband patch antenna design for WLAN and DSRC applications based on genetic algorithm Optimization,” Electromagnetics, Vol.27, pp.253-262, May 2007.

[48] J. A. Anasri, Anurag Mishra, N. P. Yadav, P. Singh and B. R. Vishvakarma, "Compact Triple U-slot loaded circular disk patch antenna for GSM mobile phone and optical communications,” Inter. Jour. Microw. Opt. Technol., Vol. 6, pp.91-99, March 2011. 
[49] A. Mishra, J.A. Ansari, P. Singh, N. P. Yadav and B. R. Vishvakarma, "L-strip feed circular disk dual resonator patches antenna for wireless communication," Wireless Personal Communications, Vol. 72, pp.795-807, September 2013.

[50] A. Singh, J, A. Ansari, K. Kamakshi, A. Mishra and M. Aneesh, "Compact notch loaded half disk patch antenna for dualband operation,” Annals of Telecommunications, Vol. 69, pp. 475-483, 2014.

[51] A. Singh , J.A. Ansari, Kamakshi, M. Aneesh, S. S. Sayeed, "L-strip proximity fed gap coupled compact semicircular disk patch antenna,” Alexandria Engineering Journal, Vol.53, pp. 61-67, 2014.

[52] A. Singh, M. Aneesh, ,K. Kamakshi, ,A. Mishra, ,J. A. Ansari, “Analysis of F-shape microstrip line fed dual band antenna for WLAN applications,” Wireless Networks, Vol. 20, pp. 133-140 January 2014.

[53] K. Noguchi, H. Rajagopalan, and Y. R. Samii, "Design of wideband/dual band E-shaped patch antennas with the transmission line mode theory,” IEEE Trans. Antennas and Propagation, Vol. 64, pp.1183-1192, 2016.

[54] S. Liu, W. Wu and Da-G. Fang, "Single-feed dual layer dual band E shaped and U-slot patch antenna for wireless communication application,” IEEE Antenna and Wireless Propagation Letters, Vol. 15, pp.468-471, 2016.

[55] C. Salvador, L. Borselli, A. Falciani and S. Maci, "Dual Frequency planar antenna at S and X bands," Electronics Letters, Vol. 31, pp. 1706-1707, Sept. 1995.

[56] G. J. Lazzi, S. S. J. Pattnaik and O. P. Gandhi, "Experimental study on compact, high gain, low SAR single and dual-band patch for cellular telephones,” IEEE Antenna Propagat. Soc. Int. Symp., Vol.1, pp. 130-133, Jun. 1998.

[57] R. Lelarat and R.J. Langley, "Dual band patch for mobile satellite system," IEE Proc. Micro. Antennas Propag., Vol.147, pp.421-430,Dec. 2000.

[58] M. S. Tong, M. Yang, Y. Chen and R. Mittra, "Finite difference time domain analysis of a stacked dual frequency microstrip planar inverted F-antenna for mobile telephone handsets," IEEE Trans. Antenna Propagat., Vol. 49, pp. 367-376, Mar. 2001

[59] Y. H. Shum, and K. M. Luk, "Design of dualband L-probe patch antenna for mobile communications," IEEE Antenna Propagat. Soc. Int. Symp., Vol. 4, pp. 94-97, July 2001.

[60] S. H. Yeh, K. L. Wong, T. W. Chiou and S. T. Fang, "Dualband planar inverted F antenna for GSM/DCS mobile phones”, IEEE Trans. Antenna Propagat.,Vol.51, pp. 1124-1126, May 2003.

[61] W. H. Chen, Z. H. Feng, M. Y. Fan and Y. Furuya, "Dualband reconfigurable antenna for wireless communication,” Microwave Opt. Technol. Lett., Vol. 40, pp. 503-505, Mar.2004.

[62] C. W. Jung and F. D. Flaviis, "A dualband antenna for WLAN applications by double rectangular patch with 4bridges,” IEEE Antenna Propagat. Soc. Int. Symp., Vol. 4, pp. 4280-4283, June 2004.

[63] H. Y. Kim, Y. A. Lee, C. H. Won and H. M. Lee, "Design of compact dualband microstrip patch antenna for GPS/K-PCS operation,” IEEE Antenna Propagat. Soc. Int. Symp., Vol.4, pp. 3529-3532, June 2004.

[64] S. H. Choi, J. K. Park, S. K. Kim and H. S. Kim, "Design of dualband antenna for the ISM band using a backed microstrip line,” Microw. Opt. Technol. Lett., Vol.41, pp. 457-460, June 2004.

[65] L. Boccia, G. Amendola and G. Di Massa, "A dual frequency microstrip antenna for high precision GPS applications,” Antenna and Wireless Propagation Letters, IEEE, Vol. 3, pp. 157-160, Dec. 2004.

[66] S. H. Hwang, W. Kwak, J. I. Moon and S. O. Park, "An internal Dualband printed antenna for CDMA/PCS handsets,” Microw. Opt. Technol. Lett., Vol.45, pp.537-540, June 2005.

[67] E. H. Lim and K.W. Leung, "Dual wideband rectangular dielectric resonator antenna for WLAN communications,” Microw. Opt. Technol. Lett., Vol.48, pp. 378-380, Feb. 2006.

[68] M. Joseph, R. K. Raj, M. N. Suma and P. Mohanan, "Compact dualband antenna for DCS/2.4 GHz WLAN applications,” Microw. Opt. Technol. Lett., Vol.48, pp.856-859, May 2006.

[69] C. Y. D. Sim and S. Y. Tu, "Dual frequency shorted patch antenna for WLAN applications," Microw. Opt. Technol. Lett., Vol.49, pp. 389-391, Feb.2007.

[70] C. Y. Huang, H. C. Lin and J. S. Kuo, "Dualband monopole antenna excited by a capacitive coupling feed for WLAN applications,” Microw. Opt. Technol. Lett., Vol. 49, pp.1135-1138, May 2007.

[71] J. Tao, C. H. Cheng and H. B. Zhu, "Compact dualband slot antenna for WLAN applications," Microw. Opt. Technol. Lett., Vol.49, pp.1203-1204, May 2007.

[72] W. Encheng and F. Shaojun, "Dualband patch antenna on magnetic substrate for WLAN communication," Microw. Opt. Technol. Lett., Vol.49, pp.1445-1447, June 2007.

[73] W. Ren, Z. Shi, H. Liu, and K. Chen, "Novel compact 2.4/5-GHz dualband T-slot antenna for WLAN operations,” Microw. Opt. Technol. Lett., Vol.49, pp. 1236-1238, June 2007.

[74] W. C. Liu, “Optimal design of dualband CPW fed G-shaped monopole antenna for WLAN application,” PIER ON LINE, Vol.74, pp.21-38, Aug. 2007.

[75] H. Rmili and J. M. Floc'h, "Design of a dualband V-shaped monopole antenna for DCS/2.4GHz WLAN operations,” Microw. Opt. Technol. Lett., Vol. 50, pp.2615-2617, Oct. 2008.

[76] W. Ren, “Compact dualband slot antenna for 2.4/5GHz WLAN applications,” PIER B, Vol.8, pp.319-327, 2008.

[77] J. N. Lee, J. H. Kim, J. K. Park and L. Y. Tseng, "Design of dualband antenna with U-shaped open stub for WLAN/UWB applications,” Microw. Opt. Technol. Lett., Vol.51, pp. 284-289, Feb.2009.

[78] L. Zhang, Y. C. Jiao, Kun Song, and Fu-Shun Zhang, “Compact dual frequency double T-shaped slot antenna for RFID application,” Microw. Opt. Technol. Lett., Vol.51, pp.1755-1757, Aug.2009.

[79] R. H. Zeng and Q. X. Chu, “A compact slot coupled dualband RFID tag antenna," Microw. Opt. Technol. Lett., Vol.51, pp.2046-2048, Sept.2009.

[80] S. H. Choi, H. C. Lee and K. S. Kwak, "A novel K-shaped dual -band antenna with a shorting pin for WLAN communications,” Microw. Opt. Technol. Lett., Vol.51, pp.2442-2444, Oct.2009. 
[81] E. Wang, J. Zheng and Y. Liu, “A novel dualband patch antenna for WLAN communication,” PIER Online C, Vol.6, pp-93-102, Feb.2009.

[82] S. Y. Park, S. J. Oh and J. K. Park, "Dualband antenna for WLAN/UWB applications,” Microw. Opt. Technol. Lett., Vol.52, pp.2188-2191, Oct. 2010.

[83] J. R. Panda and R. S. Kshetrimayum, "An F-shaped printed monopole antenna for dual-band RFID and WLAN applications,” Microw. Opt. Technol. Lett., Vol. 53, Issue 7, pp. 1478-1481, July 2011.

[84] D.-B. Lin, I-T. Tang and Y.-J. Wei, "Compact dual-band-notched CPW-fed wide-slot antenna for WLAN and WiMAX applications,” Microw. Opt. Technol. Lett., Vol. 53 pp. 1496-1501, July 2011.

[85] J.-H. Lu and Y.-H. Liu, "Novel dual-band design of planar slot array antenna for 4G LTE/WiMAX access points,” Microw. Opt. Technol. Lett., Vol.54, pp.1193-1196, May 2012.

[86] D. Batra and S. Sharma, "Dual band dielectric resonator antenna for wireless application,” International Journal of Electronics, Vol. 99, pp.1323-1331 September 2012.

[87] M. Salar Rahimi, J. Rashed-Mohassel and M.Edalatipour, "Radiation properties enhancement of a GSM/WLAN microstrip antenna using a dual band circularly symmetric EBG substrate," Antennas and Propagation, IEEE Trans., Vol.60, pp. 5491 - 5494, November2012.

[88] C. L. Tan and W. Ismail, "Compact dual band tag antenna design for radio frequency identification (RFID) application,” Progress In Electromagnetics Research C, Vol. 31, pp.29-40, 2012.

[89] L. Xiong and P. Gao, "Compact dual-band printed diversity antenna for WIMAX/WLAN applications," Progress In Electromagnetics Research C, Vol. 32, pp.151-165, 2012.

[90] N. Ojaroudi and M. Ojaroudi, "CPW-FED slot antenna for personal mobile communication service (PCS) and bluetooth applications,” Microw. Opt. Technol. Lett., Vol.55, pp. 734-737, April 2013.

[91] L.-K. Chen, T.-F. Chien and C.-H. Luo, "Dual-band wearable compact antenna for GPS and UMTS applications," Microw. Opt. Technol. Lett., Vol. 55, pp.859-863, April 2013.

[92] Y. Li, W. Li and Q. Ye, "A compact asymmetric coplanar strip-fed dual-band antenna for 2.4/5.8 GHz WLAN applications,” Microw. Opt. Technol. Lett., Vol. 55, pp.2066-2070, September 2013.

[93] U. Chakraborty, A. Kundu, S.K. Chowdhury and A.K. Bhattacharjee, "Compact dual-band microstrip antenna for IEEE 802.11a WLAN Application,” Antennas and Wireless Propagation Letters, IEEE, Vol. 13, pp. 407 - 410, 2014.

[94] Lin-Chuan Tsai, “A dual-band bow-tie-shaped CPW-fed slot antenna for WLAN applications,” Progress In Electromagnetics Research C, Vol. 47, pp.167-171, 2014.

[95] A.K. Sharma, A. Mittal, and B.V.R. Reddy, "Slot embedded dual-band patch antenna for WLAN and Wi-Max Applications,” Electronics Letters, Vol.51, pp.608-609, 2015.

[96] P.S. Bakariya, S. Dwari, M. Sarkar, and M. K. Mandal, "Proximity coupled microstrip antenna for Bluetooth, WiMax, and WLAN applications,” IEEE Antennas and wireless Propagation Letters, Vol. 14, pp.755-758, 2015.

[97] S. Mathew, M. Ameen, M. P. Jayakrishnan, P. Mohanan, and K. Vasudevan, "Compact dual polarized V slit, stub and slot embedded circular patch antenna for UTMS/WiMax/WLAN applications,” Electronics Letters, Vol. 52, pp.1425-1426, 2016.

[98] X-Q Zhu, Yong-Xin Guo, and Wen Wu, "A novel dual band antenna for wireless communication applications," IEEE Antennas and Wireless Propagation Letters, Vol. 15, pp. 516-519, 2016. 